\title{
Why hasn't evolution selected for perfect self-control?
}

\author{
Benjamin Y. Hayden
}

Department of Neuroscience and

Center for Magnetic Resonance Research

University of Minnesota,

Minneapolis, MN 55455

\section{Correspondence:}

Benjamin Y. Hayden

CMRR Building,

University of Minnesota,

Minneapolis, MN 55455

Telephone: 425-749-2341

Email: benhayden@gmail.com 


\begin{abstract}
Self-control refers to the ability to deliberately reject tempting options and instead select ones that produce greater long-term benefits. Although some apparent failures of self-control are, on closer inspection, reward maximizing, at least some self-control failures are clearly disadvantageous and non-strategic. The existence of poor self-control presents an important evolutionary puzzle because there is no obvious reason why good self-control should be more costly than poor self-control. After all, a rock is infinitely patient. I propose that self-control failures result from cases in which well-learned (and thus routinized) decision making strategies yield suboptimal choices. These mappings persist in the decision-makers' repertoire because they result from learning processes that are adaptive in the broader context, either on the timescale of learning or of evolution. Self-control, then, is a form of cognitive control and the subjective feeling of effort likely reflects the true costs of cognitive control. Poor self-control, in this view, is ultimately a result of bounded optimality.
\end{abstract}




\section{MAIN TEXT}

\section{Introduction}

Poor self-control is inimical to mental and physical health and to life success; it is associated with poverty, obesity, loneliness, and other unwanted states (de Ridder et al., 2012; Tangney et al., 2004; Story et al., 2014). It is both a symptom and a cause of diseases that increase mortality, such as addiction, depression, and obsessive-compulsive disorder (e.g. Duckworth and Seligman 2005; Quinn and Fromme 2010; Dixon et al., 2003). Because failures of self-control are costly, the ability to exert self-control can confer evolutionary benefits and ought to be subject to strongly negative selection pressure. The ubiquity of poor self-control, then, poses an important riddle: why hasn't natural selection endowed us with perfect self-control?

For present purposes, I define self-control as deliberately avoiding the choice of a tempting option so as to choose an alternative that produces greater long-term benefits. The main reason I use this definition is because it brings to the fore the evolutionarily puzzling aspects of self-control failure. This definition is not universally shared, but it is, from a reading of the literature, the closest to a consensus view available (e.g. Shenhav, 2017; Shenhav et al., 2017; Muraven and Baumeister, 2000; Baumeister et al., 1994; Mischel et al., 1996). Some other definitions include strategies that avoiding tempting contexts; my definition treats these as outside the bounds of self-controlled behavior (Fujita, 2011; Berkman et al., 2017). Other scholars have considered choices that appear to reflect poor self-control may have adaptive outcomes (Fawcett et al., 2012; Stephens, 2002; Stevens, 2014; Stephens and Anderson, 2001; Kacelnik, 2003). Such choices are interesting, as they provide insight into the evolution of cognitive faculties. However, they are not relevant to the central question I consider here, as they are reward maximizing, and thus adaptive, and not evolutionarily puzzling. One important caveat in this definition is that to be called a test of self-control, the decision-maker must know the potential outcomes (or the range of outcomes in the case of stochastic decisions).

It's not obvious why perfect self-control would be difficult to evolve. Self-control decisions are, ostensibly, just like another mental operation. Consider, for comparison, 
the example of saccadic eye movements, which, like self-control decisions, are regulated by the brain (including the prefrontal cortex) and are subject to volitional control (Yarbus, 1967). We make saccadic eye movements three to four times per second during our waking hours, without any sense of fatigue, throughout our lives. When something surprising appears in the visual field, we look at it without succumbing to the temptation to procrastinate for several days (as we might with more conventional self-control problems, such as paying a bill or reviewing a manuscript). We don't ever feel the temptation to cheat or cut corners; for example, we don't move our eyes only $80 \%$ of the way towards a target, as we might with a diet. Our oculomotor control systems, like our respiratory control systems, our form vision systems, and many others, constantly function at a high level with rare failures. So what makes economic decisions different? Why are so many of our daily value-based decisions subject to large and small selfcontrol failures?

\section{Some approaches to self-control do not help us understand why it fails}

One view of self-control, dating back at least to William James, sees it as the result of the competition between two systems (James, 1890; Baumeister and Heatherton 1996; Carver et al., 2005; Hoffman et al., 2009). These are often known as the hot and cold systems. The hot system advocates for impulsive choices and the cold system advocates for controlled ones (Metcalfe and Mischel, 1999). These two systems have at least some affiliation with Freud's idea of the id and superego, respectively (Baumeister et al., 1998). And in a more mathematical guise, this view has direct parallels to the beta and delta systems (Harris and Laibson, 2004; McClure et al., 2004). The hot vs. cold idea is supported by neuroscientific results showing a regulatory system (often dorsal and lateral) inhibiting a basic value system (often ventral and medial, e.g. Figner et al, 2010; Hare et al, 2009; McClure et al., 2004). In this two-systems view, self-control failure reflects a failure of the cold system to overrule the hot system. Despite its appeals, this view does not provide any explanation for why the hot system would ever win. That is, it simply allow for a restatement of the core mystery of self-control. 
Another important view sees self-control as an economic decision - a comparison between two differently valued options - that is not different in any substantial way from other economic decisions (Berkman et al., 2017; see also McGuire and Kable, 2015; Kurzban et al., 2013; Becker and Murphy, 1988). While self-control decisions clearly are a type of economic decision, they are of a special type. The strict similarity view ignores the most important thing about self-control: it can fail. And those failures are not just due to noise. Many cognitive processes (including economic choice) are susceptible to errors but these errors are due to noise and are independent of choices. In contrast, self-control failures always go in the same direction: succumbing to temptation. This distinction is clearest in the case of intertemporal choice tasks. In standard implementations of these tasks, preference for the shorter-sooner option is most often indicates poor self-control (Kirby and Marakovic, 1996). But on trials in which the shorter-sooner option provides a higher long-term reward rate than the larger-later alternative, then choice of the largerlater option will yield negative discount rates. This 'negative self-control' is much rarer than the alternative.

Another limitation of the economic model is that it does not readily explain the ego-dystonic nature of self-control failures. That is, it cannot explain why failure, or even the prospect of it, would evoke negative emotions (often severe ones), when economic mistakes do not (for a similar argument, see Rogeberg, 2004).

Most critically for my concerns here, the economic view cannot explain the high prevalence of self-control failure if it is just a type of miscalculation. Evolution has finely honed our minds to make good decisions (Santos and Rosati, 2015; Stephens and Krebs, 1986). It has endowed us with abilities to do cost-benefit computations that are much more complicated than many self-control problems require. For example, our brains can simultaneously track multiple fluctuating variables at many timescales (Farashahi et al., 2018; Daw et al., 2006; Pearson et al., 2010); we can detect subtle changes in probability (Nassar et al., 2010); we can anticipate others' strategies several levels deep (Camerer and Ho, 1999). Time biases don't seem to be the problem either. In foraging tasks, at least, many animals, including humans, can optimize reward rate to within a few 
percentage points of optimal (Blanchard et al., 2014; Schweighofer et al., 2006; Stephens and Krebs, 1986).

A third, not entirely distinct, view equates self-control directly with patience or with withholding a response (Stevens and Stephens, 2008; Kacelnik, 2003; Mischel and Ebbeson 2001; Rachlin, 2000). Patience is a time-centric view of self-control, and it equates poor self-control with unwillingness to wait extended periods of time to obtain better rewards. The patience perspective generally equates poor self-control with action and good self-control with inaction. Asking why patience fails involves asking how action (which would presumably be costly) accidently overcomes inaction. Prima facie, not moving one's muscles would seem to require very minimal amounts of energy. (This ignores the opportunity costs of time, which are excluded from conventional definitions of self-control failure). But why would patience be costly? This perspective is especially puzzling in light of the large number of examples of evolved patience. For example, a male rhesus macaque can wait months to gain weight in preparation for the fights associated with mating season (Strier, 2018; Rawlins and Kessler, 1986). There is no obvious reason to think these apparently lazy males are exerting months of difficult selfcontrol.

\section{Evaluating some theories about why self-control fails}

Perhaps the most influential explanation for self-control failure is the idea that control relies on a limited internal resource (Baumeister and Heatherton, 1996; Muraven and Baumeister, 2000; Baumeister et al., 1998; Inzlicht and Schmeichel, 2012). In the influential strength model, or ego depletion model, self-control is demanding in the same way that muscular movement is (Baumeister et al., 2007; Baumeister et al., 1994). That is, self-control requires effort, it depletes some central reserve, and improves with practice (Muraven et al., 1998; Baumeister et al., 98; Baumeister et al., 2006). Glucose was proposed as this energy store; perhaps self-control requires mental activity that is metabolically costly (Baumeister et al., 2006; Gailliot and Baumeister, 2007; Dvorak and 
Simons, 2009). This theory has a natural evolutionary explanation because energy is an obvious limiting factor for any organism.

One limitation of this view is that there is no obvious neuroscientific reason why self-control is metabolically costly. Another is that the strength theory is not empirically supported. Meta-analyses and large replications indicate that small study bias and publication bias likely led to over-inflated estimates of depletion effects, which may not exist at all (Carter et al., 2015; Hagger et al., 2016; Carter and McCullough, 2013; Xu et al., 2014; Inzlicht and Berkman, 2015). Likewise, the idea that glucose serves as the reservoir has been successfully challenged (Carter and McCullough, 2013; Molden et al., 2012; Vadillo et al., 2016). This is not to say that self-control does not vary systematically, or flag with fatigue, just that ego depletion cannot account for most of its effects (Muller and Apps, 2018). In any case, the prominent failures of the ego depletion hypothesis are an important motivator for the questions I raise here.

Another idea is that more self-control requires a larger brain (MacLean et al., 2014; Stevens, 2014). Failures, in this view, come from insufficient mental resources associated with brain volume - and the tradeoffs in self-control are the same as those associated with brain size. Support for this view, for example, comes from a major study comparing self-control in thirty-six species showing that absolute (and not relative) brain size predicted self-control strength across species (MacLean et al., 2014). Likewise, Stevens examined intertemporal choice performance in thirteen primate species (Stevens, 2014; see also Stevens and Muhlhof, 2012). Among other variables, absolute brain size (and again, not relative brain size), predicted self-control. These findings suggest that something about larger brains allows us to wait longer.

However, the specific tasks used in both the studies have been challenged as measures of self-control (Beran, 2015; Fawcett et al., 2012; Stephens and Anderson, 2001; Hayden, 2016). Even if these tasks measure a combination of self-control and other processes, the evidence linking brain size to self-control may instead demonstrate a link to other factors. Indeed, brain size correlates with many other factors that may contribute to preferences in these tasks, such as metabolic rate and lifespan (Stevens, 2014). More 
fundamentally, these studies do not offer an explanation of why larger brains would lead to more self-control. While it seems reasonable that larger brains lead to complex mental abilities like general intelligence and social intelligence, self-control would seem to be computationally simple (Tobin and Logue, 1994; Sol et al., 2010; Byrne and Corp, 2004; Deaner et al., 2007). It just requires a computation and comparison of reward rates associated with each option. Animals, even ones with small brains, are highly adept at estimating and maximizing reward rates (Stephens et al., 2007; Stephens and Krebs, 1986). Even bees and ants, which have minimal nervous systems can do it nimbly (Wendt and Czaczkes, 2017).

Yet another explanation for poor self-control has to do with the importance of prospection for self-control (Bulley et al., 2016). Specifically, it has been argued that episodic foresight, the ability to simulate the future and reason about it, is critical (Suddendorf and Corballis, 1997; Buckner and Carroll, 2007). According to this view, failures of self-control result from failures to prospect. This viewpoint has several limitations, however. Most importantly, self-control is more widespread in the animal kingdom than prospection is (MacLean et al., 2014). For example a rat can exhibit selfcontrol but likely has no episodic foresight (Tobin and Logue, 1994). Moreover, while self-control may benefit from prospection, it is not essential (Kwan et al., 2012; Stephens and Stevens, 2008; Craver et al., 2014). Indeed, it may be that prospection is critical for flexible self-control, but not for successful simple self-control itself (Bulley et al., 2016).

Finally, several scholars have focused on the adaptive benefits of poor self-control (Stephens and Anderson, 2001; Kacelnik, 2003). Thus, for example, patience entails both an interruption risk and a collection risk (Fawcett et al., 2012; Stephens, 2002; Kagel et al., 1986; Sozou, 1998). Both of these risks increase the opportunity cost of waiting relative to selecting the immediate option (Stephens, 2002). Likewise, self-control may be fit to environment. For example, marmosets and tamarins have diverged relatively recently but have very different ecological niches. Insectivorous tamarins move quickly to catch their prey and discount time steeply (and thus ostensibly have poor self-control); marmosets, which specialize in tree-sap exudate, need to be patient to feed and are so, but 
they discount space steeply (but, by conventional definitions, have good self-control). This approach can explain variations in self-control observed across species, including primates (Rosati et al., 2007; Stevens et al., 2005; Stevens et al., 2005; Heilbronner et al., 2008).

This perspective is valid, and is likely at least partially correct (but see Henly et al., 2007), but it does not help us with the evolutionary puzzle that interests us here. That is, if a smaller-sooner reward offers a larger expected rate of intake, then choosing it is, by my definitions here, is good - not poor - self-control. In other words, if an idealized perfectly self-controlled decision-maker would make the same choices, we cannotbased on behavior (which is all we can measure in animals) - call it a self-control failure. And in the case that self-control inarguably fails, as in a macaque that chooses smaller/sooner options more than interruption/collection risk indicates, the adaptive fit theory does not provide any explanation.

\section{The intertemporal choice task}

The intertemporal choice task has long occupied a central place in the self-control research program (Rachlin, 2000; Ainslie, 1974; Berns et al., 2007; Kacelnik and Bateson, 1996; Mazur, 1978; Kirby and Marakovic, 1996; Kurzban et al., 2013, Frederick et al., 2002). This task, which is widely used in both humans and non-human animals, involves a series of choices between options that differ in delay and magnitude. Successful self-control is defined as selection of a larger option with a greater delay or effort cost over a smaller but cheaper/sooner one. Non-human animals generally show discount factors with a half-life (i.e. discount factor, $k$ ) of a few seconds; humans show a wider range, from these short timescales to factors in the range of weeks to months, but are still impulsive (Green et al., 1994; Kirby and Herrnstein, 1995; Frederick et al, 2002).

The high discount factors typically observed in the intertemporal choice task strongly violate the principles of adaptedness (Stephens and Anderson, 2001; Stephens et al., 2004; Kacelnik, 2003; Pavlic and Passino, 2010; Pearson et al., 2010). That is, animal decision-makers that discount on the order of seconds could not possibly negotiate simple 
tradeoffs necessary to survive in the world. For a monkey with a very low (i.e., patient) discount rate of $k=0.05$, the subjective value of an option that is only $\sim 20$ seconds away would be reduced by half of its true value. An option that requires two minutes to obtain would have essentially no value. This animal obviously could not make good decisions and survive outside the lab. Indeed, strong arguments have been made that the intertemporal choice task is different in key ways from tasks animals are likely to have faced in their evolved histories (Fawcett et al., 2012; Stephens et al., 2004; Kacelnik and Bateson, 1996; Namboodiri et al., 2014; Blanchard et al., 2013). Measures of time preferences in more naturalistic tasks produce order-of-magnitude improvements in measured self-control; that is, animals seem to have better self-control if it's measured differently (Schweighofer et al., 2006; Blanchard et al., 2013, 2014, 2015; Blanchard and Hayden, 2015 Pearson et al., 2010; Stephens and Anderson, 2001; Stephens et al., 2004; Stephens and Stevens, 2008).

At a minimum, these results challenge the external validity of the form of selfcontrol measured by the intertemporal choice task (Hayden, 2016). Why would the task lack validity? Even decision-makers with perfect self-control will show apparent selfcontrol failures if they misunderstand the task (Stephens and Anderson, 2001; Stephens et al., 2004). For example, most implementations of the intertemporal choice task use a post-reward buffering structure to avoid "cheating" strategies of choosing the smaller sooner reward to get to the next trial sooner. But this stratagem only works if the animal fully understands the structure of the task. Failure to correctly understand the buffering structure will produce apparently poor self-control in a maximizing forager (Blanchard et al., 2013; Hayden, 2016). Most animals likely either misunderstand or misapply this element of the task (e.g. Stephens and Anderson, 2001; Mazur et al., 1978; Logue et al., 1985; Green et al., 1981; Fox et al., 2013).

There is a second problem that limits the interpretability of the intertemporal choice task. The traditional definition of poor self-control holds, in essence, that poorly controlled decision-makers will over-weight time relative to reward. But decision-makers with poor self-control may more readily overweight the reward dimension relative to the 
time dimension (Paglieri, 2013; Bramlett, 2012; Beran, 2015). The presence of an option that produces a large amount of food is a strong tempter (Boysen and Berntson, 1995). Indeed, the temptation to seek food and ignore costs would seem to be archetypical selfcontrol problem. Decision-makers who succumb to the temptation to choose the larger amount will, in a typical intertemporal choice task, have - by conventional definitions - a surfeit of self-control (Adessi, 2011).

The human intertemporal choice task is not usually implemented with adjusting buffers, and does not usually use primary rewards like food (but see McClure et al., 2007; Hayden et al., 2007; Pearson et al., 2010). As such it does not have the same problems the animal version does. Nonetheless, the relevance of the task to human self-control has been questioned. First, the external validity of the task is quite low, compared to other self-control tasks such as the BART task (Lejuez et al., 2002). Second, humans exhibit several anomalies that cannot be explained through the principle of discounting (reviewed in Frederick et al., 2002). For example, in many cases, humans and animals prefer sequences of rewards in which value increases over time to sequences in which value declines (Frederick et al., 2002; Hsee et al., 1991; Varey et al., 1992; Chapman, 2000; Blanchard et al., 2014). Indeed, it appears that humans preferentially use heuristic strategies that result in discounting-like behavior without discounting (Scholten and Read, 2010).

\section{Towards a cognitive control-based theory: three examples}

In moving towards considering the evolutionary causes of poor self-control, is it helpful to begin with a few concrete examples. The first comes in the form of drugs and alcohol. These are common sources of self-control problems, affect a large number of people, and can have deadly consequences. They are clearly ego-dystonic in many cases, and clearly resist even very serious and costly efforts to abstain. So, why have we not evolved the ability to resist? Notably, most drugs, at least in their potent modern forms, were not present in the environment of evolutionary adaptedness (EEA). Most addictive drugs (i.e. those that work on reward pathways) were first made available within the past 
few centuries. The industrial revolution has led to new techniques for purifying and delivering the drugs such that today's drugs of abuse are more potent and addictive than they have been at any previous point in our evolutionary history. For example, although alcohol was likely fermented several thousand years ago, until recently it had a relatively low alcohol content. So addictive drugs work by taking advantage of brain communication networks that were evolved in an environment without them. From a necessarily slow evolutionary perspective, addictive drugs are simply a very novel danger to which we have not yet evolved a solution. Overcoming the temptation to consume drugs and alcohol, then requires making use of general-purpose cognitive faculties. Drugs, then, constitute something of an edge case - we have not evolved mechanisms to overcome drugs and are forced to use - as an inferior backup - our non-specialized cognitive systems.

A second example comes from dieting. Consider that one of the more successful laboratory paradigms in humans has been the diet choice task, in which poor self-control is defined as choosing the tastier but less healthy item (e.g. Hare et al., 2009). Human food resources underwent major shifts at the time of the agricultural and then industrial revolutions - both too recent to have had major effects on the evolution of cognition. In other words, the diet available in the EEA was sufficiently limited that dieting was probably not necessary. Dieting, then, likely can only be implemented by use of deliberate cognitive resources, which conflict with the canalized and inflexible processes that lead us to seek high-calorie food. Tempting food, then, works in some ways like drugs - we have not evolved specialized mechanisms to deal with it, and must make use of a general cognitive system.

A third example comes from a trio of tasks that are often used in animal studies of self-control. In reverse contingency tasks, animals must point to one of two rewards in order to get the other (Kralik, 2005; Izquierdo and Murray, 2004; Chudasama et al., 2006; Boysen and Berntsen, 1995; Silberberg and Fujita, 1996; Stephens and Anderson, 2000; Genty 2004; Shifferman, 2009; Uher, 2008). This task is quite difficult but trainable in some animals. In accumulation tasks a reward is available at any time but builds up the 
longer the animal waits. Gaining a larger reward involves inhibiting the taking of the reward, as that would end the accumulation process (e.g., Anderson et al., 2010; Beran et al., 2002; Evans and Beran, 2007; Pelé et al., 2010; Pelé, et al., 2011). Finally, exchange tasks require an animal to keep a small reward in their possession for a period of time before trading it back to the experimenter for a bigger reward (Dufour et al., 2007; Leonardi et al., 2012). One thing that unites these tasks is that they make use of food and not symbols that represent it. Moreover, to overcome self-control the animal must do something that is normally inimical to food receipt. Thus, they involve overriding lowlevel programming aimed at maximizing caloric intake by use of deliberative overriding systems.

In these three examples of self-control, animals must use general cognitive mechanisms to perform the controlled action and override strong tendencies. These tendencies may be learned through evolutionary time, as in the innate drive for sweet and fatty foods. Or they may reflect the need to override strongly learned action patterns, as in the case of exchange tasks. In any case, what unites these clear self-control examples is the competition between a general cognitive decision-making system and specialized (either learned or hard-wired) decision-making systems.

\section{Defining self-control as a form of cognitive control}

Self-control is the result of a conflict that arises when competing desires occur. The co-occurrence of both desires requires arbitration. Failure of self-control occur when one desire - the one inconsistent with long-term goals - wins. The other desire - the one associated with poor self-control - wins because it has been given extra heft in the competition, either by evolution or by learning processes.

The brain uses sensory, visceral, and learned information to guide the adaptive selection of actions (Cisek and Pezzulo, 2016). I refer to this process as sensorimotor transformation. When a certain sensorimotor transformation is common, the brain processes it in a more efficient way. I will refer to this as automatization (Botvinick et al., 2014; Shenhav et al., 2017; Shiffrin and Schneider, 1977; Muraven et al., 2000; Miller 
and Cohen, 2001). For example, the first time I follow a route across a new campus, it requires attention and dominates awareness. However, if I walk the same path every day, it rapidly becomes automated in my mind, leaving my awareness free to wander or perform other cognitively demanding activities.

Automatization carries several very useful benefits (Miller and Cohen, 2001; Shenhav et al., 2017). Automatic responses are faster. They are less variable and more accurate. They are less susceptible to interference from outside processes. Automating responses leaves room for cognitive control, which is evidently very limited (see below), to engage in other processes. Thus, while walking, I may successfully get to my office, and even perform other complex automated behaviors, like avoiding collisions with other people, while having full capacity to mentally rehearse an important lecture.

But automatization is a double-edged sword. I can offload the processing of sensorimotor information to specialized sub-computations, but those computations are now less penetrable to modulatory influences. Thus, the efficiency that makes it beneficial means it is inaccessible to unexpected, unusual, or rapidly changing goal states. These are precisely the situations that lead to self-control failure. Failure, then, can result from an automated sensorimotor mapping doing what it is supposed to do - but the context happens to be one where the sensorimotor mapping led to a bad outcome.

Failure may also result from an inability to overcome the automated sensorimotor mapping. That is, the two necessarily compete, and the automated one sometimes wins. (If it couldn't ever win, then it would not serve its purpose of reducing cognitive load). And the ego dystonia associated with self control failure comes from the fact that the brain contains specialized systems that can recognize and signal failures. The self-control failure is not selected for in the conventional sense, but it selected for indirectly, in the sense that it is the unavoidable price worth paying in exchange for the benefits of automatization. Self-control failures are a by-product of processes that produce more efficient but less flexible decisions (Shenhav et al., 2017).

It is worth noting that this argument applies even if automatization exists on a continuum rather than in two discrete states. If we are interested in two competing 
processes, then what matters is which is relatively more automatic; if we are interested in several, then what matters is if the one associated with poor self-control is more automatic. It is also notable that controlled processes can be come automated, and then produce poor control. Consider, for example, a child learning, with difficulty, to read text; a few years later, that child is tested on the Stroop task and has difficulty performing accurately in the high conflict condition.

The processes that automate basic sensorimotor mappings operate on both long and short timescales - that is, both the evolutionary timescale and on the scale of much shorter than the lifetime of an individual decision-maker. Both processes are, for my purposes here, similar. Self-control failure can result from suboptimal responses from either learned or evolved mappings. The only important difference is that evolved responses are likely even more ingrained, more canalized, and less susceptible to changing priorities. They may require even larger exertion from the central executive to overcome. It is intriguing, in this view, that some of the most powerful cases of poor selfcontrol (food and drugs) are ones that reflect an evolutionary, not just learning mismatch (reversal tasks).

If self-control is just about cognitive control, why don't we just evolve a larger capacity for cognitive control? The answer to this question is not yet determined (Miller and Cohen, 2001; Shenhav et al., 2017; Kurzban et al., 2013). It does seem clear, however, control is quite limited (Shiffrin \& Schneider 1977; Shenhav et al., 2017). We have difficult with sustained focus and task-switching (Weissman et al., 2006; Boly et al., 2007; Monsell, 2003; Hayden et al., 2010; Logan et al., 2007). Control seems to be qualitatively different from capacities like oculomotor control or form vision, which are excellent.

One possibility is that there are basic computational principles that limit the capacity of any such complex system. For example, there is good reason to think that the brain, especially the prefrontal cortex, has many properties in common with a certain neural network type known as an attractor networks. These networks can be studied in simulations to give insight into their properties, which may reflect the properties of the 
real brain. There is evidence that the number of representations that can be kept separate within such networks is limited (Usher and Cohen, 1999; Shenhav et al., 2017). The limit on the number of representations then may impose a hard limit on processing capacity. Crucially, the problem cannot be solved by devoting more resources: they brain may not be able to increase the number of available representations because shared representations provide a critical benefit in the form of allowing generalization, insight, and novel solutions to problems (Musslick et al., 2016b; Feng et al., 2014; Musslick et al., 2016a).

\section{Implications}

By this perspective, self-control is "just" a type of economic choice (as argued by Berkman et al., 2017). But it is a special one: it is one in which at (1) least one of the options is associated with an intrinsic bias towards or against it. And that means (2) overcoming that choice requires effort. And (3) failure to do so is both costly and egodystonic. These are not features of conventional economic choices. Thus, while I agree with Berkman and colleagues, I think they bypass the most interesting part of selfcontrol, its ability to fail.

Do humans have more self-control than animals? This question, often asked, is poorly specified. The cognitive control framework lets us ask it more precisely. Do humans have a greater ability to let goals and changing task demands influence their choices - and rely less on automated mappings? The answer is likely yes, but we need more studies directly comparing the cognitive control abilities of humans and other animals (e.g. Maclean et al., 2014). These tests will have to rely on an understanding of the foraging frameworks of animals, so that measures can be designed appropriately to allow comparison (Calhoun and Hayden, 2014).

If self-control is a type of cognitive control, this suggests that much of the psychology and neuroscience of cognitive control may have direct benefits in helping us to understand self-control as well. Thus, for example, information about the neuroanatomy and neuronal mechanisms of self-control should be directly testable as 
theories of self-control. One important area for future research will be to see whether our understanding of cognitive control failure can shed insight into the mechanisms of selfcontrol failure.

From the cognitive control perspective, poor self-control is the default and good self-control is more likely to require deliberate effort (Metcalfe and Mischel, 1999). This does not mean that we will always perceive it as such. Our brains are highly practiced at deploying cognitive control flexibly and adaptively, so the conflict between controlled and automatic processes may not rise to the level of consciousness. Or it may rise to the level of consciousness but may be perceived as effortful, difficult, or just distracting. The phenomenology of self-control is poorly studied, but likely to be an important motivator for future research.

Recent work in the field of self-control and in cognition more broadly has challenged the two-systems view on empirical, theoretical, and neuroscientific grounds (Kable and Glimcher, 2009; Kurzban et al., 2013; Inzlicht and Berkman, 2015; Berkman et al., 2017; McGuire and Kable, 2015; Buckholtz et al., 2015). Nonetheless, taking a cognitive control perspective on self-control suggests that this view has at least a few merits. Specifically, any given self-control decision reflects a competition between what can be thought of as distinct brain processes. (This is true whether these two types of processes are regionally or even anatomically differentiated). That doesn't mean there are two systems; but there are two tendencies: automatic and controlled. And these types may be relative, not absolute; we may have a spectrum of processes ranging from automatic to controlled. But in many specific situations, there will only be two relevant processes competing. In that sense, one could even meaningfully label them hot and cold.

\section{Implications for the neuroscience of self-control}

The idea that self-control is a type of cognitive control suggests that we do not have a special self-control system or self-control module in the brain. That is, if selfcontrol is continuous with cognitive control, there is no region whose unique purpose (or even one of its purposes) is to drive self-control. Instead, controlled actions likely make 
use of a more general control architecture. This control architecture may be modular or may be distributed (Botvinick and Cohen, 2014; Miller, 2000; Hampshire et al., 2015; Eisenreich et al., 2017). It likely includes dorsal prefrontal regions, such as the dorsolateral prefrontal cortex and dorsal anterior cingulate cortex (Botvinick and Cohen, 2014; Miller, 2000; Ebitz and Hayden, 2016; Heilbronner and Hayden, 2016; Shenhav et al., 2017). This approach implies that neural signatures of self-control will be continuous with signatures of cognitive control. Thus, a critical test for this idea would be to compare networks involved in cognitive control with those involved in self-control. This could be done at both the neuronal level and at larger scales.

This idea also has implications about the relationship between self-control and economic choice. Our proposal, in essence, is that self-control is an economic choice in which one option is intrinsically favored over the other, but the other is more consistent with long-term goals. Standard approaches to neuroeconomics are derived from economics, and often involve binary choices, or choices between two goods or bundles of goods in which neither is default, or a priori favored. In contrast, foraging-inspired models of economic choice take as their starting point the idea that choices are between accepting and rejecting single options (Kolling et al., 2014; Kolling et al., 2016; Hayden, 2018; Hayden and Moreno-Bote, 2018). These models, in turn are inspired by ethological observations about the types of decisions that foragers make in natural environments (Stephens and Krebs, 1986; Kacelnik et al., 2011). One of the key differences between accept-reject decisions and binary choices is that we may have intrinsic tendencies to prefer accepting or rejecting, or, because they are computed differently the two types of choices may have different psychological processes and different neural substrates (Kolling et al., 2016).

This idea in turn relates to the idea of affordance competition (Cisek and Kalaska, 2010; Cisek, 2012). Embodied theories of economic choice, going back to Gibson, emphasize that control of action is the ultimate evolutionary driving force in the brain. As such, it is not surprising that we see signatures of action even in supposedly abstract reward areas (Strait et al., 2016; Yoo et al., 2018). From this perspective, stimuli we 
encounter in the environment trigger affordances or plans for potential actions to take. The decision about whether to take that action depends on some thresholding process (whose exact nature remains to be delineated). But it is this process that determines the outcome of most self-control decisions.

\section{Conclusion}

Self-control is often taken as a given: we have poor self-control, but if we tried harder we would do better. From the psychological perspective, we are flawed. But from the evolutionary perspective, we are descended from a long line of successful foragers, and every element of our psychology has some potential explanation in our evolutionary history. Thus each of our major flaws - our tendency to lower back pain, the weakness of our anterior cruciate ligaments, our tendency to get kidney stones, our inability to fly demands an explanation. Our poor self-control is a major flaw as well. We can lament it and urge ourselves to do better in the future, but we can also be a bit more objective and ask why poor self-control is so universal. While the phylogenetic origins of self-control failure remain to be worked out, the weight of evidence suggests that the neural origins lie in the domain of cognitive control. 


\section{Acknowledgements}

This work was supported by NIH R01 DA038615. I thank Amitai Shenhav, Becket Ebitz, and Habiba Azab for comments on a working version of this manuscript.

\section{References}

1. Ainslie GW. 1974 Impulse control in pigeons. J. Exp. Anal. Behav. 21, 1333221. (doi:10.1901/jeab.1974.21-485)

2. Anderson JR, Kuroshima H, Fujita K. 2010 Delay of gratification in capuchin monkeys (cebus apella) and squirrel monkeys (saimiri sciureus). J. Comp. Psychol. 124, 205-210. (doi:10.1037/a0018240)

3. Baumeister RF, Gailliot M, DeWall CN, Oaten M. 2006 Self-Regulation and Personality: How Interventions Increase Regulatory Success, and How Depletion Moderates the Effects of Traits on Behavior. J. Pers. 74, 1773-1802. (doi:10.1111/j.1467-6494.2006.00428.x)

4. Baumeister RF, Heatherton TF, Tice DM. 1994 Losing control : how and why people fail at self-regulation. Academic Press.

5. Baumeister RF, Vohs KD, Tice DM. 2007 The Strength Model of S elf-Control. Curr. Dir. Psychol. Sci. 16, 351-355. (doi:10.1111/j.1467-8721.2007.00534.x)

6. Baumeister, R. F., Bratslavsky, E., Muraven, M., \& Tice, D. M. (1998). Ego depletion: Is the active self a limited resource? Journal of Person-ality and Social Psychology, 74, 1252-1265. http://dx.doi.org/10.1037/ 0022-3514.74.5.1252

7. Becker GS, Murphy KM. 1988 A Theory of Rational Addiction. J. Polit. Econ. 96, 675-700. (doi:10.1086/261558)

8. Beran MJ. 2015 The comparative science of 'self-control': What are we talking about? Front. Psychol. 6, 1-4. (doi:10.3389/fpsyg.2015.00051)

9. Berkman ET, Hutcherson CA, Livingston JL, Kahn LE, Inzlicht M. 2017. SelfControl as Value-Based Choice. Curr. Dir. Psychol. Sci. 26, 422-428. (doi:10.1177/0963721417704394)

10. Berns GS, Laibson D, Loewenstein G. 2007 Intertemporal choice - toward an integrative framework. Trends Cogn. Sci. 11, 482-488. (doi:10.1016/J.TICS.2007.08.011)

11. Blanchard TC, Hayden BY. 2015 Monkeys are more patient in a foraging task than in a standard intertemporal choice task. PLoS One 10, 1-11. (doi:10.1371/journal.pone.0117057)

12. Blanchard TC, Pearson JM, Hayden BY. 2013 Postreward delays and systematic biases in measures of animal temporal discounting. Proc. Natl. Acad. Sci. 110, 15491-15496. (doi:10.1073/pnas.1310446110)

13. Blanchard TC, Wilke A, Hayden BY. 2014 Hot-hand bias in rhesus monkeys. $J$. Exp. Psychol. Anim. Learn. Cogn. 40, 280-286. (doi:10.1037/xan0000033)

14. Blanchard, T. C., Strait, C. E., and Hayden, B. Y. (2015b). Ramping ensemble activity in dorsal anterior cingulate neurons during persistent commitment to a decision. J. Neurophysiol. 114, 2439-2449. doi: 10.1152/jn.00711.2015 
15. Boly, M., Balteau, E., Schnakers, C., Degueldre, C., Moonen, G., Luxen, A., Phillips, C., Peigneux, P., Maquet, P., and Laureys, S. (2007). Baseline brain activity fluctuations predict somatosensory perception in humans. Proc. Natl. Acad. Sci. U.S.A. 104, 12187-12192.

16. Botvinick MM, Cohen JD. 2014 The Computational and Neural Basis of Cognitive Control: Charted Territory and New Frontiers. Cogn. Sci. 38, 12491285. (doi:10.1111/cogs.12126)

17. Boysen ST, Berntson GG. 1995 Responses to quantity: perceptual versus cognitive mechanisms in chimpanzees (Pan troglodytes). J. Exp. Psychol. Anim. Behav. Process. 21, 82-6.

18. Buckholtz JW, Martin JW, Treadway MT, Jan K, Zald DH, Jones O, Marois R. 2015 From Blame to Punishment: Disrupting Prefrontal Cortex Activity Reveals Norm Enforcement Mechanisms. Neuron 87, 1369-1380.

(doi:10.1016/j.neuron.2015.08.023)

19. Buckner RL, Carroll DC. 2007 Self-projection and the brain. Trends Cogn. Sci. 11, 49-57. (doi:10.1016/j.tics.2006.11.004)

20. Bulley A, Henry J, Suddendorf T. 2016 Prospection and the present moment: The role of episodic foresight in intertemporal choices between immediate and delayed rewards. Rev. Gen. Psychol. 20, 29-47. (doi:10.1037/gpr0000061)

21. Byrne RW, Corp N. 2004 Neocortex size predicts deception rate in primates. (doi:10.1098/rspb.2004.2780)

22. Calhoun, A. J. and Hayden, B. Y. (2015) The Foraging Brain. Current Opinion in Behavioral Sciences 5 p 24-31

23. Camerer C, Hua Ho T. 1999 Experience-weighted Attraction Learning in Normal Form Games. Econometrica 67, 827-874. (doi:10.1111/1468-0262.00054)

24. Carter EC, Kofler LM, Forster DE, McCullough ME. 2015 A series of metaanalytic tests of the depletion effect: Self-control does not seem to rely on a limited resource. J. Exp. Psychol. Gen. 144, 796-815. (doi:10.1037/xge0000083)

25. Carter EC, McCullough ME. 2013 After a pair of self-control-intensive tasks, sucrose swishing improves subsequent working memory performance. $B M C$ Psychol. 1, 22. (doi:10.1186/2050-7283-1-22)

26. Carver CS, Johnson SL, Joormann J. 2009 Two-Mode Models of Self-Regulation as a Tool for Conceptualizing Effects of the Serotonin System in Normal Behavior and Diverse Disorders. Curr. Dir. Psychol. Sci. 18, 195-199. (doi:10.1111/j.1467-8721.2009.01635.x)

27. Chapman GB. 2000 Preferences for improving and declining sequences of health outcomes. J. Behav. Decis. Mak. 13, 203-218. (doi:10.1002/(SICI)10990771(200004/06)13:2<203::AID-BDM317>3.0.CO;2-S)

28. Chudasama Y, Kralik J, Murray E. 2006 Rhesus Monkeys with Orbital Prefrontal Cortex Lesions Can Learn to Inhibit Prepotent Responses in the Reversed Reward Contingency Task. Cereb. Cortex 17, 1154-1159. (doi:10.1093/cercor/bhl025)

29. Cisek P, Kalaska JF. 2010 Neural Mechanisms for Interacting with a World Full of Action Choices. Annu. Rev. Neurosci. 33, 269-298. 
(doi:10.1146/annurev.neuro.051508.135409)

30. Cisek P, Pastor-Bernier A. 2014 On the challenges and mechanisms of embodied decisions. Philos. Trans. R. Soc. B Biol. Sci. 369, 20130479-20130479. (doi:10.1098/rstb.2013.0479)

31. Cisek, P. (2012). Making decisions through a distributed consensus. Current opinion in neurobiology 22, 927-936.

32. Craver CF, Cova F, Green L, Myerson J, Rosenbaum RS, Kwan D, BourgeoisGironde S. 2014 An Allais paradox without mental time travel. Hippocampus 24, 1375-1380. (doi:10.1002/hipo.22318)

33. Daw ND, O’Doherty JP, Dayan P, Seymour B, Dolan RJ. 2006 Cortical substrates for exploratory decisions in humans. Nature 441, 876-879. (doi:10.1038/nature04766)

34. de Ridder DTD, Lensvelt-Mulders G, Finkenauer C, Stok FM, Baumeister RF. 2012 Taking stock of self-control: A meta-analysis of how trait self-control relates to a wide range of behaviors. Personal. Soc. Psychol. Rev. 16, 76-99. (doi:10.1177/1088868311418749)

35. Deaner RO, Isler K, Burkart J, van Schaik C. 2007 Overall brain size, and not encephalization quotient, best predicts cognitive ability across non-human primates. Brain. Behav. Evol. 70, 115-24. (doi:10.1159/000102973)

36. Dixon MR, Marley J, Jacobs EA. 2003 Delay discounting by pathological gamblers. J. Appl. Behav. Anal. 36, 449-458. (doi:10.1901/jaba.2003.36-449)

37. Duckworth AL, Seligman MEP. 2005 Self-Discipline Outdoes IQ in Predicting Academic Performance of Adolescents. Psychol. Sci. 16, 939-944. (doi:10.1111/j.1467-9280.2005.01641.x)

38. Dufour V, Sterck EHM, Thierry B. In press. Chimpanzee (Pan troglodytes) Anticipation of Food Return: Coping With Waiting Time in an Exchange Task. (doi:10.1037/0735-7036.121.2.145)

39. Dvorak RD, Simons JS. 2009 Moderation of Resource Depletion in the SelfControl Strength Model: Differing Effects of Two Modes of Self-Control. Personal. Soc. Psychol. Bull. 35, 572-583. (doi:10.1177/0146167208330855)

40. Ebitz, R. B., and Hayden, B. Y. (2016). Dorsal anterior cingulate: a Rorschach test for cognitive neuroscience. Nat. Neurosci. 19. P1278-P1279. doi: $10.1038 / \mathrm{nn} .4387$

41. Eisenreich BR, Akaishi R, Hayden BY. 2017 Control without Controllers: Toward a Distributed Neuroscience of Executive Control. J. Cogn. Neurosci. 29, 1684-1698. (doi:10.1162/jocn_a_01139)

42. Evans TA, Beran MJ. 2007 Delay of Gratification and Delay Maintenance by Rhesus Macaques (Macaca Mulatta). J. Gen. Psychol. 134, 199-216. (doi:10.3200/GENP.134.2.199-216)

43. Farashahi S, Azab H, Hayden B, Soltani A. 2018 On the flexibility of basic risk attitudes in monkeys. bioRxiv 38, 282566. (doi:10.1101/282566)

44. Fawcett TW, McNamara JM, Houston AI. 2012 When is it adaptive to be patient? A general framework for evaluating delayed rewards. Behav. Processes 89, 128 
136. (doi:10.1016/j.beproc.2011.08.015)

45. Feng SF, Schwemmer M, Gershman SJ, Cohen JD. 2014 Multitasking versus multiplexing: Toward a normative account of limitations in the simultaneous execution of control-demanding behaviors. Cogn. Affect. Behav. Neurosci. 14, 129-146. (doi:10.3758/s13415-013-0236-9)

46. Figner B, Knoch D, Johnson EJ, Krosch AR, Lisanby SH, Fehr E, Weber EU. 2010 Lateral prefrontal cortex and self-control in intertemporal choice. Nat.

Neurosci. 13, 538-539. (doi:10.1038/nn.2516)

47. Fox AT, Smethells JR, Reilly MP. 2013 Flash rate discrimination in rats: Rate bisection and generalization peak shift. J. Exp. Anal. Behav. 100, 211-221. (doi:10.1002/jeab.36)

48. Frederick, S., Loewenstein, G., \& O'Donoghue, T. (2002). Time discounting and time preference: A critical review. Journal of Economic Literature, 40, 351-401.

49. Fujita K. 2011 On conceptualizing self-control as more than the effortful inhibition of impulses. Personal. Soc. Psychol. Rev. 15, 352-366. (doi:10.1177/1088868311411165)

50. Gailliot MT, Baumeister RF. 2007 The Physiology of Willpower: Linking Blood Glucose to Self-Control. Personal. Soc. Psychol. Rev. 11, 303-327. (doi:10.1177/1088868307303030)

51. Green L, Fristoe N, Myerson J. 1994 Temporal discounting and preference reversals in choice between delayed outcomes. Psychon. Bull. Rev. 1, 383-389. (doi:10.3758/BF03213979)

52. Grosch J, Neuringer A. 1981 Self-control in pigeons under the Mischel paradigm. J. Exp. Anal. Behav. 35, 1333016. (doi:10.1901/jeab.1981.35-3)

53. Hagger MS et al. 2016 A Multilab Preregistered Replication of the Ego-Depletion Effect. Perspect. Psychol. Sci. 11, 546-573. (doi:10.1177/1745691616652873)

54. Hampshire A, Sharp DJ. 2015 Contrasting network and modular perspectives on inhibitory control. Trends Cogn. Sci. 19, 445-452. (doi:10.1016/j.tics.2015.06.006)

55. Hare TA, Camerer CF, Rangel A. 2009 Self-Control in Decision-Making Involves Modulation of the vmPFC Valuation System. Science (80). 324, 646-648. (doi:10.1126/science.1168450)

56. Hayden, B. (2018). Economic choice: the foraging perspective. Curr. Opin. Behav. Sci. 24, 1-6. (doi: 10.1016/j.cobeha.2017.12.002)

57. Hayden BY, Parikh PC, Deaner RO, Platt ML. 2007 Economic principles motivating social attention in humans. Proceedings. Biol. Sci. 274, 1751-6. (doi:10.1098/rspb.2007.0368)

58. Hayden BY. 2016 Time discounting and time preference in animals: A critical review. Psychon. Bull. Rev. 23, 39-53. (doi:10.3758/s13423-015-0879-3)

59. Hayden, B., Smith, D.V. \& Platt, M. (2010) Cognitive control signals in posterior cingulate cortex. Front. Hum. Neurosci. 4:223. doi: 10.3389/fnhum.2010.00223

60. Heatherton TF, Baumeister RF. 1996 Self-Regulation Failure: Past, Present, and Future. Psychol. Inq. 7, 90-98. (doi:10.1207/s15327965pli0701_20) 
61. Heilbronner, S. R., and Hayden, B. Y. (2016). Dorsal anterior cingulate cortex: a bottom-up view. Annu. Rev. Neurosci. 39, 149-170. (doi: 10.1146/annurev-neuro070815-013952)

62. Heilbronner SR, Rosati AG, Stevens JR, Hare B, Hauser MD. 2008 A fruit in the hand or two in the bush? Divergent risk preferences in chimpanzees and bonobos. Publ. Biol. Lett. 4, 246-249. (doi:10.1098/rsbl.2008.0081)

63. Henly SE, Ostdiek A, Blackwell E, Knutie S, Dunlap AS, Stephens DW. 2007 The discounting-by-interruptions hypothesis: model and experiment. Behav. Ecol. 19, 154-162. (doi:10.1093/beheco/arm110)

64. Hofmann W, Friese M, Strack F. 2009 Impulse and Self-Control From a DualSystems Perspective. Perspect. Psychol. Sci. 4, 162-176. (doi:10.1111/j.17456924.2009.01116.x)

65. Hsee CK, Abelson RP, Salovey P. 1991 The Relative Weighting of Position and Velocity in Satisfaction. Psychol. Sci. 2, 263-267. (doi:10.1111/j.14679280.1991.tb00146.x)

66. Inzlicht M, Berkman E. 2015 Six Questions for the Resource Model of Control (and Some Answers): Six Questions. Soc. Personal. Psychol. Compass 9, 511524. (doi:10.1111/spc3.12200)

67. Inzlicht M, Schmeichel BJ. 2012 What Is Ego Depletion? Toward a Mechanistic Revision of the Resource Model of Self-Control. Perspect. Psychol. Sci. 7, 450463. (doi:10.1177/1745691612454134)

68. Izquierdo A, Suda RK, Murray EA. 2004 Bilateral Orbital Prefrontal Cortex Lesions in Rhesus Monkeys Disrupt Choices Guided by Both Reward Value and Reward Contingency. J. Neurosci. 24, 7540-7548. (doi:10.1523/JNEUROSCI.1921-04.2004)

69. Kable JW, Glimcher PW. 2009 The neurobiology of decision: consensus and controversy. Neuron 63, 733-45. (doi:10.1016/j.neuron.2009.09.003)

70. Kacelnik A, Bateson M. 1996 Risky Theories - The Effects of Variance on Foraging Decisions. Am. Zool. 36, 402-434. (doi:10.1093/icb/36.4.402)

71. Kacelnik A, Vasconcelos M, Monteiro T, Aw J. 2011 Darwin's "tug-of-war" vs. starlings" "horse-racing": how adaptations for sequential encounters drive simultaneous choice. Behav. Ecol. Sociobiol. 65, 547-558. (doi:10.1007/s00265010-1101-2)

72. Kacelnik A. 2003 The evolution of patience. , 115-138.

73. Kagel JH, MacDonald DN, Battalio RC, White S, Green L. 1986 Risk aversion in rats (Rattus norvegicus) under varying levels of resource availability. J. Comp. Psychol. 100, 95-100. (doi:10.1037/0735-7036.100.2.95)

74. Kaufman MT, Churchland MM, Ryu SI, Shenoy K V. 2014 Cortical activity in the null space: permitting preparation without movement. Nat. Neurosci. 17, 440448. (doi:10.1038/nn.3643)

75. Kirby KN, Herrnstein RJ. 1995 Preference Reversals Due to Myopic Discounting of Delayed Reward. Psychol. Sci. 6, 83-89. (doi:10.1111/j.14679280.1995.tb00311.x) 
76. Kirby KN, Marakovic NN. 1996 Delay-discounting probabilistic rewards: Rates decrease as amounts increase. Psychon. Bull. Rev. 3, 100-104. (doi:10.3758/BF03210748)

77. Kolling N, Wittmann M, Rushworth MFS. 2014 Multiple Neural Mechanisms of Decision Making and Their Competition under Changing Risk Pressure. Neuron 81, 1190-1202. (doi:10.1016/j.neuron.2014.01.033)

78. Kolling N, Wittmann MK, Behrens TEJ, Boorman ED, Mars RB, Rushworth MFS. 2016 Value, search, persistence and model updating in anterior cingulate cortex. Nat. Neurosci. 19, 1280-1285. (doi:10.1038/nn.4382)

79. Kurzban R, Duckworth A, Kable JW, Myers J. 2013 An opportunity cost model of subjective effort and task performance. Behav. Brain Sci. 36, 661-679. (doi:10.1017/S0140525X12003196)

80. Kwan D, Craver CF, Green L, Myerson J, Boyer P, Rosenbaum RS. 2012 Future decision-making without episodic mental time travel. Hippocampus 22, 1215-9. (doi:10.1002/hipo.20981)

81. Lejuez CW, Read JP, Kahler CW, Richards JB, Ramsey SE, Stuart GL, Strong DR, Brown RA. 2002 Evaluation of a behavioral measure of risk taking: The Balloon Analogue Risk Task (BART). J. Exp. Psychol. Appl. 8, 75-84. (doi:10.1037/1076-898X.8.2.75)

82. Leonardi RJ, Vick S-J, Dufour V. 2012 Waiting for more: the performance of domestic dogs (Canis familiaris) on exchange tasks. Anim. Cogn. 15, 107-120. (doi:10.1007/s10071-011-0437-y)

83. Levy JM, Namboodiri VMK, Hussain Shuler MG. 2015 Memory bias in the temporal bisection point. Front. Integr. Neurosci. 9, 44. (doi:10.3389/fnint.2015.00044)

84. Loewenstein GE, Prelec D, Loewenstein GF. 1993 Preferences for Sequences of Outcomes. Psychol. Rev. 100, 91-108.

85. Logan, G. D., Schneider, D. W., and Bundesen, C. (2007). Still clever after all these years: searching for the homunculus in explicitly cued task switching. J. Exp. Psychol. Hum. Percept. Perform. 33, 978-994.

86. Logue AW, Smith ME, Rachlin H. 1985 Sensitivity of pigeons to prereinforcer and postreinforcer delay. Anim. Learn. Behav. 13, 181-186. (doi:10.3758/BF03199271)

87. Logue AW. 1988 Research on self-control: An integrating framework. Behav. Brain Sci. 11, 665. (doi:10.1017/S0140525X00053978)

88. MacLean, E. L., Hare, B., Nunn, C. L., Addessi, E., Amici, F., Anderson, R. C., ... Barnard, A. M. (2014). The evolution of self-control. Proceedings of the National Academy of Sciences, 111, E2140- E2148. doi:10.1073/pnas.1323533111

89. Mazur JE, Logue AW. 1978 Choice in a "self-control" paradigm: effects of a fading procedure. J. Exp. Anal. Behav. 30, 11-7. (doi:10.1901/JEAB.1978.30-11)

90. McClure SM, Ericson KM, Laibson DI, Loewenstein G, Cohen JD. 2007 Time Discounting for Primary Rewards. J. Neurosci. 27, 5796-5804. (doi:10.1523/JNEUROSCI.4246-06.2007) 
91. McClure SM, Laibson DI, Loewenstein G, Cohen JD. 2004 Separate neural systems value immediate and delayed monetary rewards. Science 306, 503-7. (doi:10.1126/science.1100907)

92. McGuire JT, Kable JW. 2013 Rational temporal predictions can underlie apparent failures to delay gratification. Psychol. Rev. 120, 395-410. (doi:10.1037/a0031910)

93. McGuire JT, Kable JW. 2015 Medial prefrontal cortical activity reflects dynamic re-evaluation during voluntary persistence. Nat. Neurosci. 18, 760-766. (doi:10.1038/nn.3994)

94. Metcalfe J, Mischel W. 1999 A hot/cool-system analysis of delay of gratification: Dynamics of willpower. Psychol. Rev. 106, 3-19. (doi:10.1037/0033295X.106.1.3)

95. Miller EK, Cohen JD. 2001 An Integrative Theory of Prefrontal Cortex Function. Annu. Rev. Neurosci. 24, 167-202. (doi:10.1146/annurev.neuro.24.1.167)

96. Mischel W, Cantor N, Feldman S. 1996 Principles of self-regulation: The nature or willpower and self-control. In Social psychology: Handbook of basic principles (eds E Higgins, A Kruglanski), pp. 329-360. New York: Guildford Press.

97. Molden DC, Hui CM, Scholer AA, Meier BP, Noreen EE, D'Agostino PR, Martin V. 2012 Motivational Versus Metabolic Effects of Carbohydrates on Self-Control. Psychol. Sci. 23, 1137-1144. (doi:10.1177/0956797612439069)

98. Monsell, S. (2003). Task switching. Trends Cogn. Sci. 7, 134-140.

99. Müller T, Apps MAJ. 2018 Motivational fatigue: A neurocognitive framework for the impact of effortful exertion on subsequent motivation. Neuropsychologia doi:10.1016/J.NEUROPSYCHOLOGIA.2018.04.030

100. Muraven M, Baumeister RF. 2000 Self-regulation and depletion of limited resources: Does self-control resemble a muscle? Psychol. Bull. 126, 247-259. (doi:10.1037/0033-2909.126.2.247)

101. Muraven M, Tice DM, Baumeister RF. 1998 Self-Control as Limited Resource: Regulatory Depletion Patterns. J. Pers. Soc. Psychol. 74, 774-789. 102. Musslick S, Dey B, Özcimder K, Patwary MMA, Willke TL, Cohen JD. 2016 Controlled vs. Automatic Processing: A Graph-Theoretic Approach to the Analysis of Serial vs. Parallel Processing in Neural Network Architectures. Proc. 38th Annu. Conf. Cogn. Sci. Soc. , 1547-1552.

103. Nassar MR, Wilson RC, Heasly B, Gold JI. 2010 An approximately Bayesian delta-rule model explains the dynamics of belief updating in a changing environment. J. Neurosci. 30, 12366-78. (doi:10.1523/JNEUROSCI.082210.2010)

104. Paglieri F. 2013 The costs of delay: waiting versus postpoing in intertemporal choice. J. Exp. Anal. Behav. 99, 362-377. (doi:10.1002/jeab.18)

105. Pavlic TP, Passino KM. 2010 When rate maximization is impulsive. Behav. Ecol. Sociobiol. 64, 1255-1265. (doi:10.1007/s00265-010-0940-1)

106. Pearson JM, Hayden BY, Platt ML. 2010 Explicit information reduces discounting behavior in monkeys. Front. Psychol. 1, 1-8. 
(doi:10.3389/fpsyg.2010.00237)

107. Pelé M, Dufour V, Micheletta J, Thierry B. 2010 Long-tailed macaques display unexpected waiting abilities in exchange tasks. Anim. Cogn. 13, 263-271. (doi:10.1007/s10071-009-0264-6)

108. Pelé M, Micheletta J, Uhlrich P, Thierry B, Dufour V. 2011 Delay Maintenance in Tonkean Macaques (Macaca tonkeana) and Brown Capuchin Monkeys (Cebus apella). Int. J. Primatol. 32, 149-166. (doi:10.1007/s10764-0109446-y)

109. Pezzulo G, Cisek P. 2016 Navigating the Affordance Landscape:

Feedback Control as a Process Model of Behavior and Cognition. Trends Cogn.

Sci. 20, 414-424. (doi:10.1016/J.TICS.2016.03.013)

110. Quinn PD, Fromme K. 2010 Self-regulation as a protective factor against risky drinking and sexual behavior. Psychol. Addict. Behav. 24, 376-385. (doi:10.1037/a0018547)

111. Rachlin H, Green L. 1972 Commitment, choice and self-control1. J. Exp. Anal. Behav. 17, 1333886. (doi:10.1901/jeab.1972.17-15)

112. Rachlin H. 2000 The science of self-control. Harvard University Press.

113. Rangel A, Hare T. 2010 Neural computations associated with goaldirected choice. Curr. Opin. Neurobiol. 20, 262-270.

(doi:10.1016/j.conb.2010.03.001)

114. Rawlins RG, Kessler MJ. 1986 The Cayo Santiago macaques : history, behavior, and biology. State University of New York Press.

115. Rogeberg O. In press. Taking Absurd Theories Seriously: Economics and the Case of Rational Addiction Theories. Philosophy of Science. 71(3).

116. Rosati AG, Stevens JR, Hare B, Hauser MD. 2007 The Evolutionary Origins of Human Patience: Temporal Preferences in Chimpanzees, Bonobos, and Human Adults. Curr. Biol. 17, 1663-1668. (doi:10.1016/J.CUB.2007.08.033)

117. Santos LR, Rosati AG. 2015 The Evolutionary Roots of Human Decision Making. Annu. Rev. Psychol. 66, 321-347. (doi:10.1146/annurev-psych-010814015310)

118. Schneider W, Shiffrin RM. 1977 Controlled and automatic human information processing: I. Detection, search, and attention. Psychol. Rev. 84, 166. (doi:10.1037/0033-295X.84.1.1)

119. Scholten M, Read D. 2010 The psychology of intertemporal tradeoffs. Psychol. Rev. 117, 925-944. (doi:10.1037/a0019619)

120. Schweighofer N, Shishida K, Han CE, Okamoto Y, Tanaka SC, Yamawaki S, Doya K. 2006 Humans Can Adopt Optimal Discounting Strategy under Real-Time Constraints. PLoS Comput. Biol. 2, e152.

(doi:10.1371/journal.pcbi.0020152)

121. Shallice T, Burgess PW. 1991 Deficits in strategy application following frontal lobe damage in man. Brain 114 ( Pt 2), 727-41.

122. Shenhav A, Musslick S, Lieder F, Kool W, Griffiths TL, Cohen JD, Botvinick MM. 2017 Toward a Rational and Mechanistic Account of Mental 
Effort. Annu. Rev. Neurosci. 40, 99-124. (doi:10.1146/annurev-neuro-072116031526)

123. Shenhav A. 2017 The Perils of Losing Control: Why Self-Control Is Not Just Another Value-Based Decision. Psychol. Inq. 28, 148-152.

(doi:10.1080/1047840X.2017.1337407)

124. Shiffrin RM, Schneider W. 1977. Controlled and automatic information processing: II. Perceptual learning, automatic attending, and a general theory. Psychol. Rev. 84:127-90

125. Silberberg A, Fujita K. 1996 Pointing At Smaller Food Amounts In An Analogue Of Boysen And Berntson's (1995) Procedure. J. Exp. Anal. Behav. 66, 143-147. (doi:10.1901/jeab.1996.66-143)

126. Sol D, Bacher S, Reader SM, Lefebvre L. 2008 Brain size predicts the success of mammal species introduced into novel environments. Am. Nat. 172 Suppl 1, S63-71. (doi:10.1086/588304)

127. Sozou PD. 1998 On hyperbolic discounting and uncertain hazard rates.

Proc. R. Soc. B Biol. Sci. 265, 2015-2020. (doi:10.1098/rspb.1998.0534)

128. Stephens DW, Anderson D. 2001 The adaptive value of preference for immediacy: when shortsighted rules have farsighted consequences. Behav. Ecol. 12, 330-339. (doi:10.1093/beheco/12.3.330)

129. Stephens DW, Anderson D. In press. The adaptive value of preference for immediacy: when shortsighted rules have farsighted consequences. Behav. Ecol. 12, 330-339.

130. Stephens DW, Brown JS, Ydenberg RC. 2007 Foraging : behavior and ecology. University of Chicago Press.

131. Stephens DW, Kerr B, Fernández-Juricic E. 2004 Impulsiveness without discounting: the ecological rationality hypothesis. Proceedings. Biol. Sci. 271, 2459-65. (doi:10.1098/rspb.2004.2871)

132. Stephens DW. 2002 Discrimination, discounting and impulsivity: a role for an informational constraint. Philos. Trans. R. Soc. Lond. B. Biol. Sci. 357, 1527-37. (doi:10.1098/rstb.2002.1062)

133. Stevens JR, Cushman FA, Hauser MD. 2005 Evolving the Psychological Mechanisms for Cooperation. Annu. Rev. Ecol. Evol. Syst. 36, 499-518.

(doi:10.1146/annurev.ecolsys.36.113004.083814)

134. Stevens JR, Hallinan E V, Hauser MD. 2005 The ecology and evolution of patience in two New World monkeys. Biol. Lett. 1, 223-6.

(doi:10.1098/rsbl.2004.0285)

135. Stevens JR, Mühlhoff N. 2012 Intertemporal choice in lemurs. Behav. Processes 89, 121-127. (doi:10.1016/J.BEPROC.2011.10.002)

136. Stevens JR, Stephens DW. 2008 Patience. Curr. Biol. 18, R11-2. (doi:10.1016/j.cub.2007.11.021)

137. Stevens, JR. 2014 Evolutionary pressures on primate intertemporal choice. Proceedings. Biol. Sci. 281, 20140499. (doi:10.1098/rspb.2014.0499) 
138. Strait, C.E., Sleezer, B.J., Blanchard, T.C., Azab, H., Castagno, M.D., and Hayden, B.Y. (2016). Neuronal selectivity for spatial positions of offers and choices in five reward regions. Journal of neurophysiology 115, 1098-1111.

139. Strier KB. 2018 Primate Behavioral Ecology. 5th edn. T\&F India.

140. Suddendorf T, Corballis MC. 1997 Mental time travel and the evolution of the human mind. Genet. Soc. Gen. Psychol. Monogr. 123, 133-67.

141. Tangney, J.P., Baumeister, R.F., \& Boone, A.L. (2004). High self-control predicts good adjustment, less pathology, better grades, and interpersonal success. Journal of Personality, 72, 271-322.

142. Tobin H, Logue AW. 1994 Self-control across species (Columba livia, Homo sapiens, and Rattus norvegicus). J. Comp. Psychol. 108, 126-133. (doi:10.1037/0735-7036.108.2.126)

143. Uher J, Asendorpf JB. In press. Personality in the behaviour of great apes: temporal stability, cross-situational consistency and coherence in response.

(doi:10.1016/j.anbehav.2007.04.018)

144. Usher M, Cohen JD. 1999 Short Term Memory and Selection Processes in a Frontal-Lobe Model. pp. 78-91. Springer, London. (doi:10.1007/978-1-44710813-9 7)

145. Vadillo MA, Gold N, Osman M. 2016 The Bitter Truth About Sugar and Willpower. Psychol. Sci. 27, 1207-1214. (doi:10.1177/0956797616654911)

146. Varey C, Kahneman D. 1992 Experiences extended across time:

Evaluation of moments and episodes. J. Behav. Decis. Mak. 5, 169-185.

(doi:10.1002/bdm.3960050303)

147. Wegner DM, Schneider DJ, Carter SR, White TL. Paradoxical Effects of Thought Suppression.

148. Weissman, D. H., Roberts, K. C., Visscher, K. M., and Woldorff, M. G. (2006). The neural bases of momentary lapses in attention. Nat. Neurosci. 9, 971978.

149. Wendt S, Czaczkes TJ. 2017 Individual ant workers show self-control. Biol. Lett. 13, 20170450. (doi:10.1098/rsbl.2017.0450)

150. Xu X, Demos KE, Leahey TM, Hart CN, Trautvetter J, Coward P, Middleton KR, Wing RR. 2014 Failure to Replicate Depletion of Self-Control. PLoS One 9, e109950. (doi:10.1371/journal.pone.0109950)

151. Yarbus A. Eye Movements and Vision. 1st edn. New York, NY: Springer.

152. Yoo, S. B. M, Sleezer, B. J., and Hayden, B. Y. (2018). Robust encoding of spatial information in orbitofrontal cortex and striatum. Journal of Cognitive Neuroscience. 30(6) 898-913. 